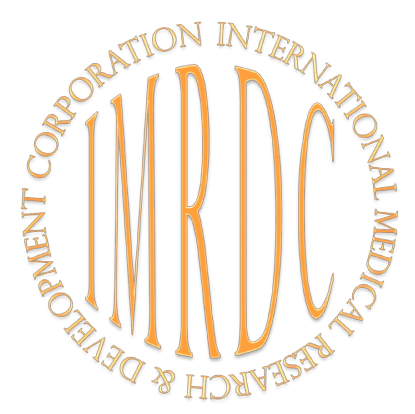

\title{
The Search for Molecular Prognostic Markers of Diabetic Nephropathy in Patients with Type 2 Diabetes Mellitus
}

\author{
V. M. Ibragimov, $\mathrm{PhD}^{1}$; I.V. Sarvilina, $\mathrm{PhD}, \mathrm{ScD}^{2 *}$; M.M. Batiushin, $\mathrm{PhD}, \mathrm{ScD}^{3}$ \\ ${ }^{1}$ Dagestan State Medical Academy, the Republic of Dagestan, Makhachkala, the Russian Federation \\ ${ }^{2}$ Medical Centre "Novomeditsina", Rostov-on-Don, the Russian Federation \\ ${ }^{3}$ Rostov-on-Don State Medical University, Rostov-on-Don, the Russian Federation
}

\begin{abstract}
The purpose of this study was to search for molecular prognostic markers of diabetic nephropathy (DN) in patients with type 2 diabetes mellitus (T2DM).

The study included 205 patients with T2DM and DN (stages 1 to 4). All patients were stratified by the MDRD equation. The control group included 30 healthy individuals. All T2DM patients were divided into 4 groups depending on the DN stages. Group 1 included 42 patients with DN-Stage 1 (prenephropathy), Group 2 included 48 patients with DN-Stage 2 (incipient nephropathy); Group 3 included 65 patients with DN-Stage 3 (overt nephropathy), and Group 4 included 50 patients with DN-Stage 4 (kidney failure). Molecular phenotyping of urine was processed with methods of proteomics: the prefractionation, the separation of proteins with standard sets (MB-HIC C8 Kit, MB-IMAC Cu, MB-Wax Kit, «Bruker», USA), matrix-assisted laser desorption-ionization time-of-flight mass spectrometry (MALDI-TOF-MS/MS, Ultraflex II, «Bruker», USA). The data of the molecular interactions and functional features of proteins were received with STRING 10.0 database. Potentially new molecular markers of DN development were identified. (Int J Biomed. 2016; 6(1):65-69.).
\end{abstract}

Keywords: type 2 diabetes mellitus; diabetic nephropathy; proteomics; molecular markers.

\section{Introduction}

Diabetic nephropathy DN is a chronic disease that affects 366 million people worldwide (6.4\% of the adult population) and is expected to rise to 552 million by 2030 [1]. In Russia, the prevalence of $\mathrm{DN}$ among patients with type 2 diabetes mellitus (T2DM) is an average of $8 \%$ that below world values in 5 times. Active screening of patients with T2DM reveals that the true prevalence of DN exceeds that registered in various regions of Russia by 2 to 8 times. The epidemiology of DN in T2DM has been insufficiently investigated because it is extremely difficult to determine the time when DN begins. One of the main causes of mortality among T2DM patients is DN that leads to terminal renal failure (5\% to $10 \%$ of cases of T2DM) [2-4]. Experimental and clinical trials performed from 1998 until 2014 showed that hyperglycemia $[5,6,7]$, hyperglycemia [8], a high level of creatinine in the blood, glomerular hyperfiltration [9], proteinuria [10], arterial hypertension [11], and anemia [12] play an important role in

*Corresponding author: Irina V. Sarvilina, PhD, ScD. CEO of Medical Centre «Novomeditsina», Rostov-on-Don, Russia. E-mail: isarvilina@mail.ru the development of DN in T2DM patients. Genetic factors (genes of perlecan, N-deacetylase, IL-1, the receptor to IL-1, aldose reductase, catalase, SOD2, paraoxonase) can directly to define the development of DN together with the genes (genes of angiotensinogen, renin, ACE, AT2R1), defining human cardiovascular diseases [13].

The molecular pathogenesis of DN in T2DM patients cannot be described only on the basis of standard methods of clinical research. Modern methods and technologies of proteomic analysis allow us to search new prognostic markers and to explore pathways of DN in T2DM patients. Currently, we need progress in the development and clinical application of new molecular screening tests reflecting key genomicproteomic interactions underlying DN in T2DM patients.

The purpose of this study was to search for molecular prognostic markers of DN in T2DM patients.

\section{Materials and Methods}

The study was prospective comparative cohort with parallel design. The study conducted in accordance with WMA Declaration of Helsinki (1964-2013) and the permission of the Ethics Committee of the Rostov State Medical University. It 
included 205 patients with T2DM and DN (stages 1 to 4). The control group included 30 healthy individuals.

All patients were stratified by the MDRD equation. Patients corresponded to the criteria for the DN classification proposed by the Committee on Diabetic Nephropathy [14]. Clinical-anamnestic characteristics of T2DM patients with DN are presented in Table 1. All T2DM patients were divided into 4 groups depending on the DN stages. Group 1 included 42 patients with DN-Stage 1 (prenephropathy), Group 2 included 48 patients with DN-Stage 2 (incipient nephropathy); Group 3 included 65 patients with DN-Stage 3 (overt nephropathy), and Group 4 included 50 patients with DN-Stage 4 (kidney failure). The duration of DN was 10.5 years.

\section{Table 1.}

Clinical-anamnestic characteristics of the studied patients

\begin{tabular}{|c|c|c|c|c|c|}
\hline Variable & $\begin{array}{c}\text { Group } 1 \\
(\mathrm{n}=42)\end{array}$ & $\begin{array}{c}\text { Group } 2 \\
(\mathrm{n}=48)\end{array}$ & $\begin{array}{c}\text { Group } 3 \\
(\mathrm{n}=65)\end{array}$ & $\begin{array}{c}\text { Group } 4 \\
(\mathrm{n}=50)\end{array}$ & $\begin{array}{l}\text { Control } \\
(\mathrm{n}=30)\end{array}$ \\
\hline $\operatorname{Sex}(M / F), n$ & $24 / 18$ & $23 / 25$ & $27 / 38$ & $24 / 26$ & $14 / 16$ \\
\hline Age, years & $59.2 \pm 2.5$ & $61.3 \pm 2.7$ & $60.5 \pm 2.3$ & $61.7 \pm 2.9$ & $59.5 \pm 1.7^{\&}$ \\
\hline Weight, $\mathrm{kg}$ & $85.5 \pm 1.7$ & $87.4 \pm 1.8$ & $86.3 \pm 1.5$ & $86.1 \pm 1.3$ & $75.6 \pm 1.2$ \\
\hline Height, $\mathrm{cm}$ & $171.2 \pm 1.7$ & $169.4 \pm 1.6$ & $170.5 \pm 1.6$ & $170.4 \pm 1.4$ & $170.5 \pm 1.6$ \\
\hline$B M I, \mathrm{~kg} / \mathrm{m}^{2}$ & $31.4 \pm 1.2$ & $30.2 \pm 1.1$ & $31.0 \pm 1.2$ & $30.9 \pm 1.2$ & $26.1 \pm 0.8$ \\
\hline $\begin{array}{l}\text { T2DM } \\
\text { duration, yrs }\end{array}$ & $10.3 \pm 1.1$ & $9.7 \pm 1.0$ & $10.2 \pm 1.2$ & $9.9 \pm 1.1$ & - \\
\hline $\begin{array}{l}\text { T2DM Total risk } \\
\text { score: } \\
\text { Low }(<7) \\
\text { Slightly ele- } \\
\text { vated }(7-11) \\
\text { Moderate }(12-14) \\
\text { High }(15-20) \\
\text { Very high }(>20)\end{array}$ & $\begin{array}{c}- \\
12 \\
19 \\
7 \\
4\end{array}$ & $\begin{array}{c}- \\
6 \\
24 \\
12 \\
6 \\
\end{array}$ & $\begin{array}{l}- \\
- \\
35 \\
17 \\
13\end{array}$ & $\begin{array}{c}- \\
- \\
22 \\
19^{*} \\
9\end{array}$ & $\begin{array}{l}26 \\
4 \\
- \\
- \\
-\end{array}$ \\
\hline $\begin{array}{l}\text { Degree of } \\
\text { metabolic } \\
\text { compensation: } \\
H b A 1 c<9 \% \\
H b A 1 c: 9-10 \% \\
H b A 1 c>10 \%\end{array}$ & $\begin{array}{c}40 \\
2^{\wedge} \\
-\end{array}$ & $\begin{array}{c}24 * * \\
24 \\
-\end{array}$ & $\begin{array}{c}2 * * * \\
42 \\
21 \\
\end{array}$ & $\begin{array}{l}- \\
32 \\
18\end{array}$ & $\begin{array}{l}- \\
- \\
-\end{array}$ \\
\hline $\begin{array}{l}\text { BP JNC7 } \\
\text { category [15] } \\
\text {-Normal } \\
\text {-Prehypertension } \\
\text {-Stage1 H } \\
\text {-Stage2 H }\end{array}$ & \begin{tabular}{|c|} 
\\
- \\
4 \\
$28 * * * / \wedge \wedge$ \\
$10^{\wedge \wedge / * * *}$
\end{tabular} & $\begin{array}{c}- \\
4 \\
18^{\wedge \wedge} \\
26\end{array}$ & $\begin{array}{c}- \\
7 \\
9^{\wedge \wedge \wedge} \\
49^{\# \#}\end{array}$ & $\begin{array}{c}- \\
- \\
15^{\# / *} \\
35^{*}\end{array}$ & $\begin{array}{c}30 \\
- \\
- \\
-\end{array}$ \\
\hline $\begin{array}{l}\text { ECG data: } \\
\text {-Sokolov-Lyon } \\
\text { index } \\
\left(S V 1+R V_{5-6}\right) \\
>3.5 m V, n \\
\text {-Cornell voltage } \\
\text { QRS duration } \\
\text { product } \\
\left(>244 m V^{*} m s\right), n\end{array}$ & 24 & 35 & 47 & $42^{\wedge \wedge \wedge \wedge}$ & - \\
\hline $\begin{array}{l}\text { Stages of } \\
\text { retinopathy: } \\
\text {-mild NPDR } \\
\text {-moderate NPDR } \\
\text {-severe NPDR } \\
\text {-PDR }\end{array}$ & $\begin{array}{c}12 * * * \\
28 \\
2 \\
-\end{array}$ & $\begin{array}{c}10 \\
30 \\
8 \\
-\end{array}$ & $\begin{array}{c}3^{\# \#} \\
35 \\
20 " \\
7\end{array}$ & $\begin{array}{c}- \\
25 \\
12^{\# \# \#} \\
13^{\#}\end{array}$ & $\begin{array}{l}- \\
- \\
- \\
-\end{array}$ \\
\hline
\end{tabular}

$H$ - hypertension; NPDR - Nonproliferative diabetic retinopathy; $P D R$ - proliferative diabetic retinopathy;

$P=0.000$ for: *1 vs. $4 ; * * 2$ vs. $3 ; * * * 3$ vs. $1 ; \wedge 1$ vs. 2,1 vs. 3,1 vs. 4

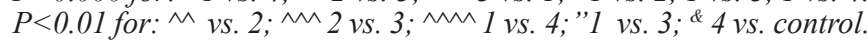
$P<0.05$ for: ${ }^{3}$ vs. $4 ;{ }^{2} 2$ vs. 3; "\#\# vs. 1.
T2DM risks were evaluated with a special Type 2 Diabetes risk assessment form designed by Professor J.Tuomilehto (http://www.diabetes.fi/files/502/eRiskitestilomake.pdf).

At the stage of data collection and screening, we applied standard methods for identification of DN and DM: the assessment of the patient's complaints, medical history, physical examination, 24-hour ABPM, ECG, the ultrasonography of kidney (Doppler spectrum of the intrarenal arteries in conjunction with evaluation of the renal cortical echogenicity, SonoAce R3, Samsung Medison, South Korea), blood and urine tests, biochemical analysis of blood and urine (ELISA, Siemens 2000, Germany), the estimation of T2DM compensation by HbA1c levels (Randox Laboratories Ltd., UK), coagulogram («Instrumentation Laboratory», USA), the measurement of albumin/creatinine in the urine. MAU (urinary albumin excretion of $30-300 \mathrm{mg} / 24$ hours) was assessed by a semi-quantitative method using test strips for the determination of protein in the urine, in compliance with the rules for collecting morning urine. GFR was estimated by the Cockcroft-Gault formula.

Molecular phenotyping of biosamples (urine) was processed with methods of proteomics: the prefractionation, the separation of proteins with standard sets (MB-HIC C8 Kit, MB-IMAC Cu, MB-Wax Kit, «Bruker», USA), matrixassisted laser desorption-ionization time-of-flight mass spectrometry (MALDI-TOF-MS/MS, Ultraflex II, «Bruker», USA). The partially identified sequences were then submitted to "BLAST protein-protein" and screened against the Homo sapiens Swissprot database to check if this identification matched the MASCOT-identification (Matrix Science). The data of the molecular interactions and functional features of proteins were received with STRING 10.0 database.

The duration of therapy (hypoglycemic drugs: glibenclamide, metformin, pioglitazone, insulin glargine; antihypertensive drugs: amlodipine, valsartan; hypolipidemic drug - fenofibrate; antiplatelet drug - acetylsalicylic acid) was 9.2 years.

Statistical analysis of the survey data was performed using the software "Statistica 12.0" (Statsoft, Russia). Baseline characteristics were summarized as frequencies and percentages for categorical variables and as mean \pm SEM for continuous variables. Student's unpaired t-tests were used to compare two groups for data with normal distribution. Comparisons between three groups were performed with the one-way ANOVA with Tukey's post-hoc test. Group comparisons with respect to categorical variables are performed using $\chi 2$ tests with Yates correction or, alternatively, Fisher's exact test when expected cell counts were $<5$. A probability value of $\mathrm{P}<0.05$ was considered statistically significant.

\section{Results}

Parameters of coagulogram, blood test, uric acid, and potassium in the serum were in the range of reference values. Ultrasonographic signs of DN were detected in all patients: high resistive indices were obtained in the region of the arcuate or the interlobar arteries in patients with elevated serum creatinine levels. 
We noted a significant increase in indicators of 24-h daytime and nighttime SBP and DBP and heart rate (daytime SBP: Group $1-115.2 \pm 3.1 \mathrm{mmHg}$, Group $2-134.7 \pm 3.9$ $\mathrm{mmHg}$, Group $3-145.4 \pm 4.1 \mathrm{mmHg}$, and Group $4-159.1 \pm 4.7$ $\mathrm{mmHg}, P 1 / 2<0.001, P 1 / 3<0.001, P 1 / 4<0 ., 001$; daytime DBP: Group $1-66.7 \pm 2.1 \mathrm{mmHg}$, Group $2-72.8 \pm 2.4 \mathrm{mmHg}$, Group $3-82.0 \pm 2.8 \mathrm{mmHg}$, and Group $4-89.5 \pm 3.3 \mathrm{mmHg}$, $P 1 / 2<0.001, P 1 / 3<0.001, P 1 / 4<0.001$; nighttime SBP: Group 1 - 115.4 $\pm 1.8 \mathrm{mmHg}$, Group $2-120.5 \pm 2.3 \mathrm{mmHg}$, Group $3-129.4 \pm 2.6 \mathrm{mmHg}$, and Group $4-134.6 \pm 3.2 \mathrm{mmHg}$, $P 1 / 2<0.001, P 1 / 3<0.001, P 1 / 4<0.001$; nighttime DBP: Group 1-66.8 $\pm 1.4 \mathrm{mmHg}$, Group $2-75.2 \pm 1.6 \mathrm{mmHg}$, Group $3-$ $81.5 \pm 1.7 \mathrm{mmHg}$, and Group $4-89.3 \pm 1.9 \mathrm{mmHg}, P 1 / 2<0.001$, $P 1 / 3<0.001, P 1 / 4<0.001$; heart rate: Group $1-72.3 \pm 1.2 \mathrm{bpm}$, Group $2-79.5 \pm 1.3 \mathrm{bpm}$, Group $3-85.3 \pm 1.5 \mathrm{bpm}$, and Group $4-88.2 \pm 1.8 \mathrm{bpm}, P 1 / 2<0.001, P 1 / 3<0.001, P 1 / 4<0.001)$ in Groups 2, 3, and 4 compared to Group 1.

All these changes are associated with a higher expression of urine proteins in the progression of epithelial-to-mesenchymal transition (EMT) and changes in the extracellular matrix (ECM) in kidneys in T2DM patients with DN. Proteomic analysis helps in the detection of differences in the component composition of the urine proteins in patients with DN of varying stages compared with the control group (Table 2). Molecules interact among themselves and with other molecules as participants in universal pathways in T2DM patients with DN, which are the key elements for EMT formation and changes in ECM: Smad, p38 MAPK, TLRs, Wnt, mTOR, Notch, small GTPase and Hedgehog, PI3K/AKT- signaling pathways.
Bioinformatics analysis has revealed the presence of molecules that are the participants of the universal pathways of $\mathrm{DN}$ and the molecular interactions involved.

\section{Discussion}

Proteomic analysis has revealed an increase in the absolute number of T2DM patients with DN with an expression of proteins performing certain biological functions and having various localizations in the intra - and extracellular spaces (Table 2). Major typical morphological changes are the result of EMT: an increase of the mesangial matrix, thickening of the glomerular basement membranes, and expansion of the tubulointerstitial space due to increased amounts of ECM. As mentioned above, all EMT events are regulated by multiple intracellular signaling pathways. We consider the functional activity of some proteins in this molecular process.

Fibronectin is found in the normal glomerular mesangial matrix; an enhanced fibronectin accumulation with high expression in urine is observed in DN. This fact could be associated with locally stimulated production of the insoluble or cellular form of fibronectin in mesangial and epithelial cells. Ceruloplasmin is more difficult to be filtered by the glomerulus than albumin. We observed higher urinary ceruloplasmin excretion in patients with DN compared to controls, even in the normoalbuminuric phase. Ceruloplasmin is a promising marker of damaged glomerulus in DN, but further studies are necessary to characterize its functional role in the progression of the disease.

Table 2.

Qualitative profile of urine proteins in T2DM patients with $\mathrm{DN}$

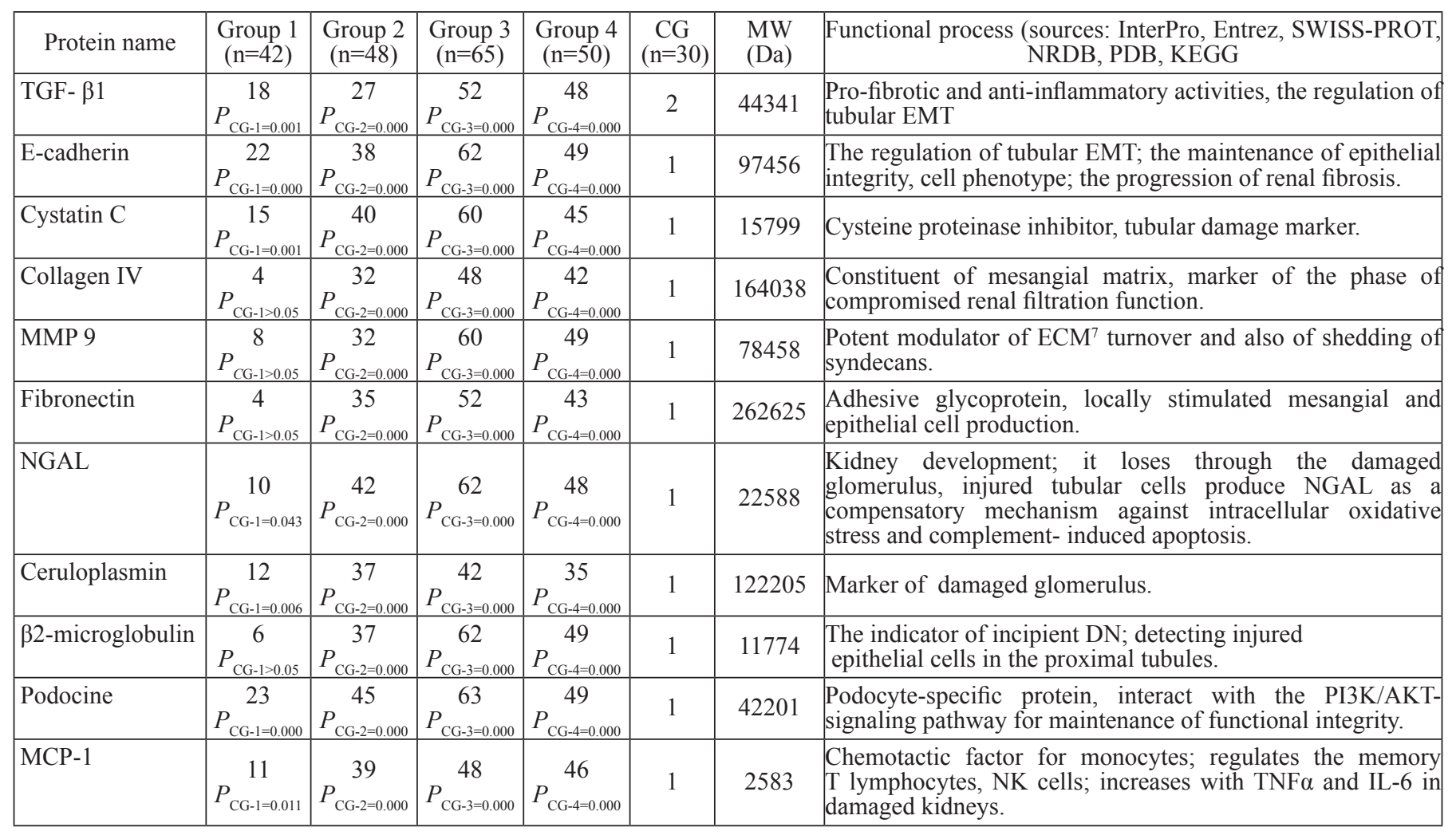

$C G$ - control group; $M W$ - molecular weight; P-value between groups based on Fisher's Exact Test 
E-cadherin is expressed in the membrane and cytoplasm of renal tubular epithelial cells, and its expression is decreased in DN compared with healthy controls. E-cadherin is identified as DN-related biomarker, which is specifically increased in urine of DN patients.

We revealed a high expression of urinary cystatin $\mathrm{C}$, a tubular damage marker, which is associated with the progression of type $2 \mathrm{DN}$. In healthy subjects, cystatin $\mathrm{C}$ is freely filtered by the renal glomeruli and entirely reabsorbed in the proximal tubule. Increased urinary cystatin $\mathrm{C}$ has been recognized as the marker of renal tubular dysfunction [16-18].

The data suggest that high urinary expression of autocrine factors including TGF $\beta$, MCP-1 and NGAL is associated with DN progression. Obviously, the autocrine signaling network stimulated the hypertrophy, expansion of the mesangial matrix and atrophy of proximal tubules. Bioinformatic analysis suggested that elevated ET-1 secretion may evoke autocrine cytokine- and chemokine-based signaling.

Transforming growth factor- $\beta$ TGF- $\beta$ has a broad spectrum of biological functions in a variety of cell types. It is widely accepted that TGF- $\beta$ and its downstream Smad cascade is a key mediator in the pathogenesis of renal fibrosis both in experimental models and in human kidney diseases [19-20].

TGF- $\beta$ mediates progressive renal fibrosis by stimulating extracellular matrix production, while inhibiting its degradation. TGF- $\beta$ is also considered to induce EMT of the injured tubule epithelial cells, whereas the in vivo relevance of EMT remains controversial. In diabetic nephropathy, TGF- $\beta$ also mediates mesangial matrix accumulation [21].

Neutrophil gelatinase-associated lipocalin (NGAL) is a protein belonging to the lipocalin superfamily initially found in activated neutrophils, in accordance with its role as an innate antibacterial factor. However, it subsequently was shown that many other types of cells, including in the kidney tubule, may produce NGAL in response to various injuries. In DN, an increased quantity of circulating NGAL could be lost through the damaged glomerulus. Injured tubular cells may actively produce NGAL as a compensatory mechanism against oxidative stress and complement-induced apoptosis in cells. NGAL may become one of the most promising nextgeneration biomarkers in clinical nephrology and beyond [22].

Monocyte chemoattractant protein-1 (MCP-1/CCL2) is one of the key chemokines that regulate migration and infiltration of monocytes/macrophages,memory T lymphocytes, and natural killer (NK) cells.

Podocyte specific proteins are early biomarkers of DN, especially podocin. The podocyte is a specialized visceral epithelial cell that helps to establish the glomerular filtration barrier and prevents protein loss, along with the glomerular basement membrane and the endothelial cell layer. Occurrence of podocytopenia (decreased number) and podocyturia (podocytes in urine) in DN are well established [23-25] Podocyte loss initiates the process of glomerulosclerosis by accelerating synechiae between podocytes and the glomerular basement membrane. In DN, altered expression of podocyte specific proteins such as synaptopodin, podocin and nephrin have been described [26].

We observed increased renal production of type IV collagen, a prominent constituent of the thickened basement membrane and expanded mesangium. The excretion of collagen IV has been found in DN (stages of microalbuminuria or overt proteinuria), which demonstrates the progression of glomerular injury with additional structural damage induced by increased synthesis of type IV collagen in extramesangial sites.

We found also the activation of urinary MMP9. This fact could be associated with excessive accumulation of ECM, which is thought to contribute to the development of DN. MMP9 may remodel ECM in DN.

Each protein molecule in the functional group interacts with other protein molecules. For example, the molecular interactions of NGAL are presented in Fig. 1. The concentration of NGAL increases in the urine of T2DM patients with DN that was most pronounced in the groups with incipient and overt nephropathy.

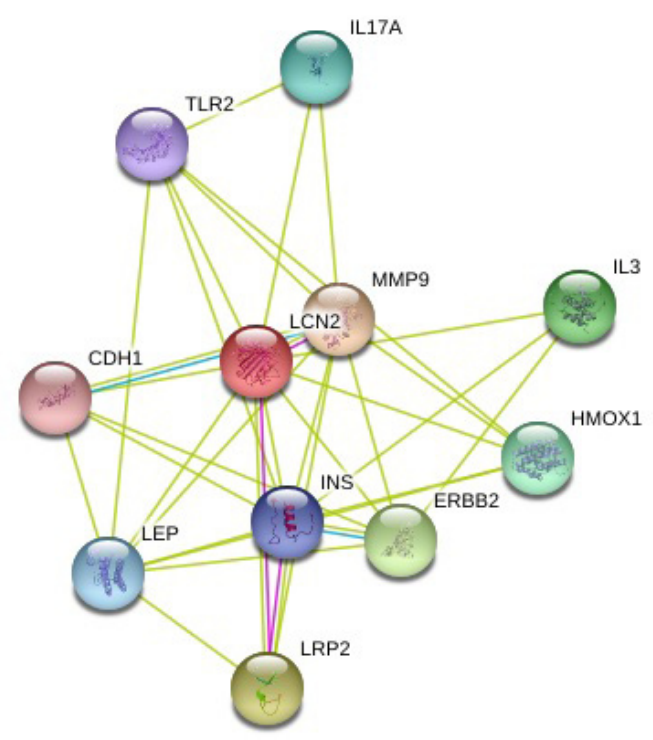

Fig. 1. Molecular interactions of NGAL (STRING 10.0 database)

LCN2, lipocalin-2; MMP-9, matrix metallopeptidase 9; LRP2, low density lipoprotein-related protein 2; ERBB2, erythroblastic leukemia viral oncogene homolog 2 (neuro/glioblastoma derived oncogene homolog); IL3, interleukin 3 (colony-stimulating factor, multiple); HMOX1, heme oxygenase (decycling) 1; IL-17A interleukin 17A; $\mathbf{L E P}$, leptin; INS, insulin; $\boldsymbol{T L R 2}$, toll-like receptor 2; CDH1, cadherin 1, type 1, E-cadherin (epithelial cadherin).

\section{Conclusion}

The study identified the biomarkers of tubular damage that have a key role in the development and progression of DN. The research into signaling pathways and the molecules that are involved in ECM formation may help in developing strategies to prevent $\mathrm{DN}$.

\section{Competing interests}

The authors declare that they have no competing interests. 


\section{References}

1. IDF Diabetes Atlas, Fifth Edition. International Diabets Federation, Brussels, Belgium; 2011.

2. Shestakova M, Shamalova M. Diabetic nephropathy: clinic, diagnostic, therapy. Dedov II, editor. M: Medicine; 2009. [in Russian].

3. Shlipak M. Diabetic nephropathy: preventing progression. BMJ Clin Evid. 2010;2010. pii: 0606.

4. KDOQI Clinical Practice Guideline for Diabetes and CKD: 2012 Update. Am J Kidney Dis. 2012;60(5):850-86.

5. King, P, Peacock I, Donnelly R. The UK Prospective Diabetes Study (UKPDS): clinical and therapeutic implications for type 2 diabetes / P. King, I.Peacock, R. Donnelly. Br J Clin Pharmacol. 1999; 48(5):643-8.

6. Intensive Blood Glucose Control and Vascular Outcomes in Patients with Type 2 Diabetes. ADVANCE Collaborative Group, Patel A, MacMahon S, Chalmers J, Neal B, Billot L, Woodward M, et al. N Engl J Med. 2008;358(24):2560-72.

7. Wood AJ, Churilov L, Perera N, Thomas D, Poon A, MacIsaac RJ, et al. Estimating glomerular filtration rate: Performance of the CKD-EPI equation over time in patients with type 2 diabetes. J Diabetes Complications. 2016;30(1):49-54.

8. Hall J, Brands M, Dixon W, Smith MJJr. Obesity-induced hypertension. Renal function and systemic hemodynamics. Hypertension. 1993;22(3):292-9.

9. Rask-Madsen C, King GL. Vascular complications of diabetes: mechanisms of injury and protective factors. Cell Metab. 2013;17(1):20-33.

10. Brenner BM, Cooper ME, de Zeeuw D, Keane WF, Mitch WE, Parving HH, et al.; RENAAL Study Investigators. Effects of losartan on renal and cardiovascular outcomes in patients with type 2 diabetes and nephropathy. N Engl J Med. 2001;345(12):861-9.

11. Van Buren PN, Toto R.Hypertension in diabetic nephropathy: epidemiology, mechanisms, and management. Adv Chronic Kidney Dis. 2011;18(1):28-41.

12. Stauffer ME, Fan T. Prevalence of Anemia in Chronic Kidney Disease in the United States. PLoS One. 2014;9(1): e84943.

13. Ha SK, Seo JK. Insertion/deletion polymorphism in ACE gene as a predictor for progression of diabetic nephropathy. Kidney Int Suppl.1997;60:S28-32.

14. Haneda M, Utsunomiya K, Koya D, Babazono T, Moriya T, Makino H, et al.; Joint Committee on Diabetic Nephropathy. A new Classification of Diabetic Nephropathy 2014: a report from Joint Committee on Diabetic Nephropathy. J Diabetes Investig. 2015;6(2):242-6.

15. The Seventh Report of the Joint National Committee on Prevention, Detection, Evaluation, and Treatment of High Blood Pressure: the JNC 7 report. Chobanian AV, Bakris GL, Black HR, Cushman WC, Green LA, Izzo JL Jr, et al.; National Heart, Lung, and Blood Institute Joint National Committee on Prevention, Detection, Evaluation, and Treatment of High Blood Pressure; National High Blood Pressure Education Program Coordinating Committee. JAMA. 200321;289(19):2560-72

16. Kim SS, Song SH, Kim IJ, Jeon YK, Kim BH, Kwak IS, et al. Urinary cystatin $\mathrm{C}$ and tubular proteinuria predict progression of diabetic nephropathy. Diabetes Care. 2013;36(3):656-61.

17. Conti M, Moutereau S, Zater M, Lallali K, Durrbach A, Manivet $\mathrm{P}$, et al. Urinary cystatin $\mathrm{C}$ as a specific marker of tubular dysfunction. Clin Chem Lab Med. 2006;44(3):288-91. 18. Lan HY. Diverse roles of TGF-beta/Smads in renal fibrosis and inflammation. Int J Biol Sci 2011;7:1056-67.

19. Bottinger EP. TGF-beta in renal injury and disease. Semin Nephrol 2007;27:309-20.

20. Lan HY. Tubular epithelial-myofibroblast transdifferentiation mechanisms in proximal tubule cells. Curr Opin Nephrol Hypertens 2003;12:25-29.

21. Yanagita M. Inhibitors/antagonists of TGF- $\beta$ system in kidney fibrosis. Nephrol Dial Transplant. 2012;27(10):368691.

22. Bolignano D, Donato V, Coppolino G, Campo S, Buemi A, Lacquaniti A, Buemi M. Neutrophil gelatinase-associated lipocalin (NGAL) as a marker of kidney damage. Am J Kidney Dis. 2008;52(3):595-605.

23. Jim B, Ghanta M, Qipo A, Fan Y, Chuang PY, Cohen HW, et al. Dysregulated nephrin in diabetic nephropathy of type 2 diabetes: a cross sectional study. PLoS One. 2012;7(5):e36041. 24. Nakamura T, Ushiyama C, Suzuki S, Hara M, Shimada $\mathrm{N}$, Ebihara I, et al. Urinary excretion of podocytes in patients with diabetic nephropathy. Nephrol Dial Transplant. 2000;15(9):1379-83.

25. White KE, Bilous RW, Marshall SM, El Nahas M, Remuzzi G, Piras G, et al. Podocyte number in normotensive type 1 diabetic patients with albuminuria. Diabetes. 2002;51(10):3083-9.

26. Doublier S, Salvidio G, Lupia E, Ruotsalainen V, Verzola D, Deferrari G, et al. Nephrin expression is reduced in human diabetic nephropathy: evidence for a distinct role for glycated albumin and angiotensin II. Diabetes. 2003; 52(4):1023-30. 